\title{
Being Mesolithic in Life and Death
}

\author{
Hannah Cobb ${ }^{1} \cdot$ Amy Gray Jones ${ }^{2}$ (D)
}

Published online: 25 August 2018

(c) The Author(s) 2018

\begin{abstract}
Fifty years ago, approaches to Mesolithic identity were limited to ideas of 'Man the Hunter' and 'Woman the Gatherer', while evidence of non-normative practice was ascribed to 'shamans' and to 'ritual', and that was that. As post-processual critiques have touched Mesolithic studies, however, this has changed. In the first decade of the 21st century a strong body of work on Mesolithic identity in life, as well as death, has enabled us to think beyond modern Western categories to interpret identity in the Mesolithic. These studies have addressed the nature of personhood and relational identities, the body, and the relationship between human and otherthan-human persons. Our paper reviews these changing approaches, offering a series of case studies from a range of different sites that illustrate how identity is formed and transformed through engagements with landscapes, materials, and both living and dead persons. These are then developed to advocate an assemblage approach to identity in the Mesolithic.
\end{abstract}

Keywords Mesolithic $\cdot$ Britain $\cdot$ Ireland $\cdot$ Identity $\cdot$ Assemblages $\cdot$ Death

\section{Introduction: What is Identity?}

In this paper we explore a key question: How did people conceive of their identities in Mesolithic Britain and Ireland? That is to say, What was it to be Mesolithic in life, and in death? And what approaches can we employ to answer this through the archaeological record? The argument that this paper presents demonstrates that, in fact, the question of identity is inseparable from the other themes interrogated in this JWP special issue: the tools that people used; the plants and animals that they engaged with; the structures that they built, incorporating these materials; the land,

Hannah Cobb

hannah.cobb@manchester.ac.uk

$\triangle$ Amy Gray Jones

a.grayjones@chester.ac.uk

1 School of Arts, Languages and Cultures, University of Manchester, Manchester, UK

2 Department of History \& Archaeology, University of Chester, Chester, UK 
waterways and seas through which they moved, and through which their bodies were transformed in life and in death, all constituted Mesolithic identities. But before we explore this perspective further, it is important to consider what we mean by identity, and how such a conception of identity has arisen in Mesolithic studies.

Identity is a difficult term to define, but we can describe it broadly as the way in which people conceive of themselves and their relationship to the world around them, and how others, in turn, perceive them. The explicit consideration of identity is, seemingly, a very recent concern for British and Irish Mesolithic studies. Indeed, until the late 1990s, the prevailing argument was that exploring identity was an interpretive leap too far, due to the nature of the archaeological record. Yet whilst such approaches claimed not to be able to get at behaviours and identities, their conception, through a modern, empirical and Cartesian framework of dualisms, such as subject/object and mind/body, created a series of contradictions. Studies that adhere to modern empiricism categorise the material record in a way that both implicitly and explicitly translates into statements about prehistoric hunter-gatherer identity. For example, the study of Mesolithic mortuary practices (e.g. Clark and Neeley 1987; O'Shea and Zvelebil 1984), projected post-war concerns with the ascription of an individual's status and rank based on their age, sex, and the material wealth associated with their burial. By making explicit proclamations of prehistoric huntergatherer identity in terms of modern Western correlates of status and rank, such discussions ultimately relate to how we in the modern West conceive of ourselves, rather than providing any new understanding of prehistoric hunter-gatherers.

Such accounts, albeit inadvertently, perpetuate very specific, and usually very normative, values central to modern Western identity. Consequently they are little more than an exercise in modern identity politics, which in turn is firmly bound with concepts of economic value and the objectification and subjugation of nature by culture that have arisen in modernity (Thomas 2004). Nowhere is this observation clearer than in interpretations of gender and sexual identities. For almost as long as they have been studied, Mesolithic communities have been the subject of a series of naturalised assumptions about gender and sexuality. These can be most explicitly seen in the way that archaeological material such as lithic scatters or faunal assemblages are interpreted in terms of the economic tasks they represent. Whilst drawing upon empirical data and ethnographic observations to reconstruct these tasks, such approaches often also assume gendered divisions of labour, whereby large game hunting is carried out by men and the collection of plant foods or the processing of hides is undertaken by women (e.g. Grøn 1995, 2003; Murphy 1996). These arguments rest not only on the construction of gendered identities in modern, normative terms of 'male' and 'female', but inherent within them are modern power and value systems. Thus, the 'male' activity of hunting was regularly ascribed more value than gathering activities. However the 1980s mark a turning point and, in the light of feminist critiques in archaeology and anthropology, the 'Man the Hunter' model, and the associations of the primacy of hunting, rightfully received a sustained critique (for example, see papers in Dahlberg 1981 and overviews in Finlay 2006). Such a critique has illustrated that gender is a cultural construction, and that the values ascribed to gendered identities are equally culturally specific. The notion of 'Man the Hunter' and the value placed upon supposedly male activities have, therefore, 
been exposed as representations of modern Western constructions of gendered identities rather than anything which existed in the past. Nonetheless, the legacy of this model within our interpretation of prehistoric hunter-gatherers still remains, and is most explicit in interpretations of tool types, where hunting tools such as microliths were suggested to have been used by men, whereas tools for the processing of plants and animals, such as scrapers, were used by women. Indeed Finlay (2006) has illustrated that the associations between gender and tool type have fundamentally shaped interpretations of hunter-gatherer identity to the extent that different tool types have simply been seen to equate to the presence of men or women (but see Finlay 2006 for an excellent alternative to this).

Despite the impact of high-profile feminist critiques of this issue within huntergatherer archaeology generally (e.g. Dahlberg 1981), and in specific relation to the Mesolithic of Britain and Ireland (Cobb 2005; Finlay 2006), Mesolithic research has continued to reproduce Westernised concepts of normalised heterosexual identity and nuclear familial relationships into the twenty-first century. For example, where gendered spaces are suggested, based on tool-use, this in turn leads to interpretations which uncritically assume the modern Western heterosexual family unit as norm (e.g. Grøn 2003). Furthermore, where dietary differentiations have been identified, interpretations of exogamous marriage practices (e.g. Schulting and Richards 2001) further reinforce notions of normative heterosexual practices and identities (Cobb 2005).

By the late 1990s, a number of Mesolithic scholars had begun to question many of these assumptions regarding identity. To do so they turned to a series of alternative ethnographies about identity. The question of how personal identity, or personhood, has been constructed in non-Western societies has been of concern in anthropological studies since the early twentieth century, and since the 1980s a range of ethnographic works have radically reconfigured this concept. The crux of this work has been the deconstruction of the perceived universality of Western personal identity and the notion of the individual. In contrast, a series of ethnographic accounts have demonstrated a range of alternatives to Westernised perspectives (summarised in Fowler 2004). These show that, in contrast to modern Western personhood, where the individual is bound by and defined by their own skin, for others, personal identity is conceived of in dividual terms. In these contexts, the body is understood as permeable (changed by the flow, in and out, of different substances) or partible (changed by the removal or addition of parts of the person-where material culture is also understood as part of persons) (see Fowler 2004 for an account of these concepts). In these dividual understandings of personhood, identity is not fixed and not defined by the body alone. Rather, it is fluid and changing, and identity is a process (Craib 1998).

A more recent development in the explicit and implicit discussions of identity within prehistory has been a closer consideration of the concept of the body (e.g. Robb and Harris 2013). This has grown from an awareness that more traditional approaches to prehistory, and the narratives they produce, project a further set of problematic assumptions about the conceptualisation of the body in the past. Specifically, accounts often omit embodied engagements with the world entirely in an attempt to remain 'objective', instantly making universalising statements 
and assumptions about the nature of past bodily actions in modern, Western and particularly alienated terms (Dobres 2000). Bodies are not alienated from the rest of the material world. As humans we are forever entwined within a process of interpretation of the world around us, and we are forever reacting to our interpretations and reformulating these (Heidegger 1962). Thus embodied practices are fundamental to the formation of identity.

Such approaches to personhood have provided an extraordinarily important basis for a radical rethink of Mesolithic identity. Crucially those who have explored these approaches (such as Finlay 2003) have not simply supplanted one universalising set of assumptions about identity with another. Nor have they simply and uncritically applied ethnographic analogies (such as Finlay's description of a specifically Melanesian concept of personhood formation) to the past. Instead they have used these alternative understandings to think through a wide variety of evidence in particularly diverse areas, including interpretations of identity through analyses of the body and mortuary contexts (e.g. Conneller 2006; Strassburg 2000); interpretations of faunal data and human/animal relationships (e.g. Conneller 2004; Overton 2014); interpretations of sexual and gendered identities (Cobb 2005; Schmidt 2005; Strassburg 2000); and interpretations of the formation of identity through everyday material culture use and skilled technical practice (Cobb 2014; Conneller 2005; Finlay 2003, 2006, 2014; Warren 2006). What is important in these approaches is that their stance on materials, bodies, and the relationship between the two is radically different to a standard empiricist account. Crucially, they demonstrate that material culture never exists in isolation from the physical bodies that use it, and these bodies are never neutral or value free.

In studies of the Mesolithic in the UK and Ireland these approaches have been used to great effect. Conneller (2006) has suggested that the lack of clear burials and cemeteries in the British Mesolithic may be explained by the conceptualisation of identities in the period as divisible or distributable, to the extent that bodies were simply not interred, but rather were disarticulated and circulated through meaningful social contexts. Outside the mortuary context, at the site of Star Carr in northeast Yorkshire, the presence of 21 modified antler frontlets has repeatedly drawn interpretations of ritualistic practices in which the frontlets acted as masks (Clark 1954; and see Conneller 2004, 2011). Such an interpretation involves a modern Western understanding of the individual as bounded and distinct from-and thus hidden or masked by-the frontlets. In contrast, Conneller has drawn upon perspectivist accounts of non-Western understandings of human-animal relationships to suggest that rather than disguise or hide human bodies, such masks actually revealed and transformed them, as part of wider performances that produced human and animal identities (Conneller 2004, p. 50). The productivity of this approach is further illustrated through Conneller's extension of it to all the different types of animal-human interactions that took place at the site. Through the working of hide, and the making and use of animal bones as tools, teeth as beads and skin as clothes, Conneller suggests there existed an 'ambiguity about where human bodies end and animal bodies start. Parts of humans transform animals, who in turn alter and extend human bodies' (Conneller 2004, p. 47). 
Another innovative example is Finlay's (2003) discussion of microliths and multiple authorship. Finlay has suggested that, during the Mesolithic, tool production involved a complex entanglement of relationships best illustrated through the example of composite microlithic tools. Drawing upon Melanesian ethnographies, Finlay suggests that these are likely to have been multiply authored, with several people making the microliths required, and probably group efforts required to gather and prepare the wood, resin and twine that would then enable the microliths to be hafted (Finlay 2003). Thus the production of tools would have demanded connections, between persons and between different materials from diverse sources, individual bodily practices, and group actions. The production and use of composite microlithic tools therefore required practices of fragmentation of persons, materials, the essences of places, and the social transformation and renegotiation of all of these (Warren 2006), to engender multiply authored identities (Finlay 2003). Finlay's arguments provide a powerful way of reformulating not just studies of microlithic technology, but Mesolithic technical engagements in general. This has led Warren (2006) to argue that understanding tools as a nexus for social relations in the Mesolithic provides an innovative means for examining elements such as the production and negotiation of identity.

The examples cited here take us part of the way in the narrative of these new approaches to identity. They are examples that inspired us, the authors of this paper, and subsequently our own studies have taken the examination of identity further in studies of life and death. In the rest of this paper we outline these developments.

\section{Death and Identity: Bodies that Matter}

One of the most instructive ways to examine the production of identity is to explore the treatment of the body in death. However, evidence for mortuary practice in the Mesolithic of Britain and Ireland is often regarded as poor. In contrast to other parts of northern Europe, inhumations are scarce, and the record is dominated by disarticulated human remains from a range of different contexts, not all of which are recognisably funerary. Of c. 28 sites where human remains have been recovered, there are only four where inhumation of complete bodies may have taken place (Aveline's Hole, Gough's Cave, Greylake [all Somerset], and Tilbury [Essex]). Of the remainder, two consist of cremated material deposited in pits (Hermitage [Co. Limerick] and Langford [Essex]), whilst the rest are represented by single elements or groups of disarticulated remains in coastal and inland caves, middens and palaeochannels (see summaries by Meiklejohn et al. 2011; Meiklejohn and Woodman 2012). In the first comprehensive review of this material, Conneller (2006) argued that it represented deliberate forms of mortuary practice characterised by disarticulation. This was a significant first step, both in addressing the nature of the British and Irish material and in highlighting its potential for elucidating our understanding of Mesolithic mortuary behaviour. It led to a series of projects exploring the treatment of the body (Gray Jones 2011), deposition within middens (Hellewell 2015) and new approaches to identifying fragmented remains (Charlton 2016). 
Whilst Conneller identified disarticulation as an intentional practice, her work was not able to address the specific forms of activity that took place. The human body can become disarticulated by various means at different stages after death during its transformation from fleshed cadaver to dry skeleton, and by a variety of agents. The specific practices involved, we would argue, are a key element in our understanding of the character of these interactions with the dead. Comparative studies of disarticulated material from northern Europe (Gray Jones 2011) have provided a broader context within which to understand the practices that may have produced the material from Britain and Ireland. This survey showed that there were a variety of ways of treating the body, many of which may produce disarticulated remains. These include evidence for secondary burial practices, 'collective' burial in caves where remains were defleshed, disarticulated and commingled, dismemberment of the fleshed body, cremation, and decapitation and skull burial (see review in Gray Jones 2011). The practice of manipulating dead bodies has also been recorded in some cemeteries, where elements were removed from graves and presumably deposited elsewhere (e.g. Nilsson Stutz 2003).

Whilst some of the British and Irish material lacks detailed contextual information, making differentiation between deliberate human action and post-depositional processes difficult, there are a number of sites where practices comparable to those in Europe can be recognised. The remains from the Oronsay middens, for example, may indicate exposure of the body (Meiklejohn et al. 2005), whilst cut-marks on an ulna from Kent's Cavern reflect dismemberment (Schulting et al. 2015). What is more, numerous examples of isolated or small groups of disarticulated elements have been recorded that may represent sites where disarticulated material has been deliberately deposited, whilst in Ireland there is evidence for the manufacture of objects from human remains (Woodman 2015). These practices demonstrate ways of dealing with the body that are often multi-staged, extending both temporally and spatially. Potentially some sites reflect different phases within the same process of treating/fragmenting the body, such as excarnation at one place, removal of elements to another, and deposition at yet another location (Gray Jones 2011).

These practices reveal the nature of bodily engagement with the dead and help us to explore the materiality of the human body in both life and death. If we accept that identity is continually produced and reformulated through the relationships between people, places, animals and materials, then these engagements with dead bodies are also important for understanding identity. Through their manipulation and disarticulation, bodies and parts of them were removed, curated, circulated, used and deposited, and became part of the material world. As such, the remains of the dead become an active part of material expressions of relational identities. We will illustrate the ways in which we can explore these identities through three case studies.

The first of these focuses on the late Mesolithic shell midden of Cnoc Coig, one of five middens on the island of Oronsay (W. Scotland) (see Fig. 1). Excavations by Mellars throughout the 1970s revealed a complex stratigraphy of repeated occupations centred around a large hearth and hut-like structure surrounded by accumulations of shell midden material (Mellars 1987; Meiklejohn et al. 2005). These accumulations consisted of inter-tidal molluscs (mostly limpet) and crustaceans, the remains of fish, seals and marine birds, as well as bone, 


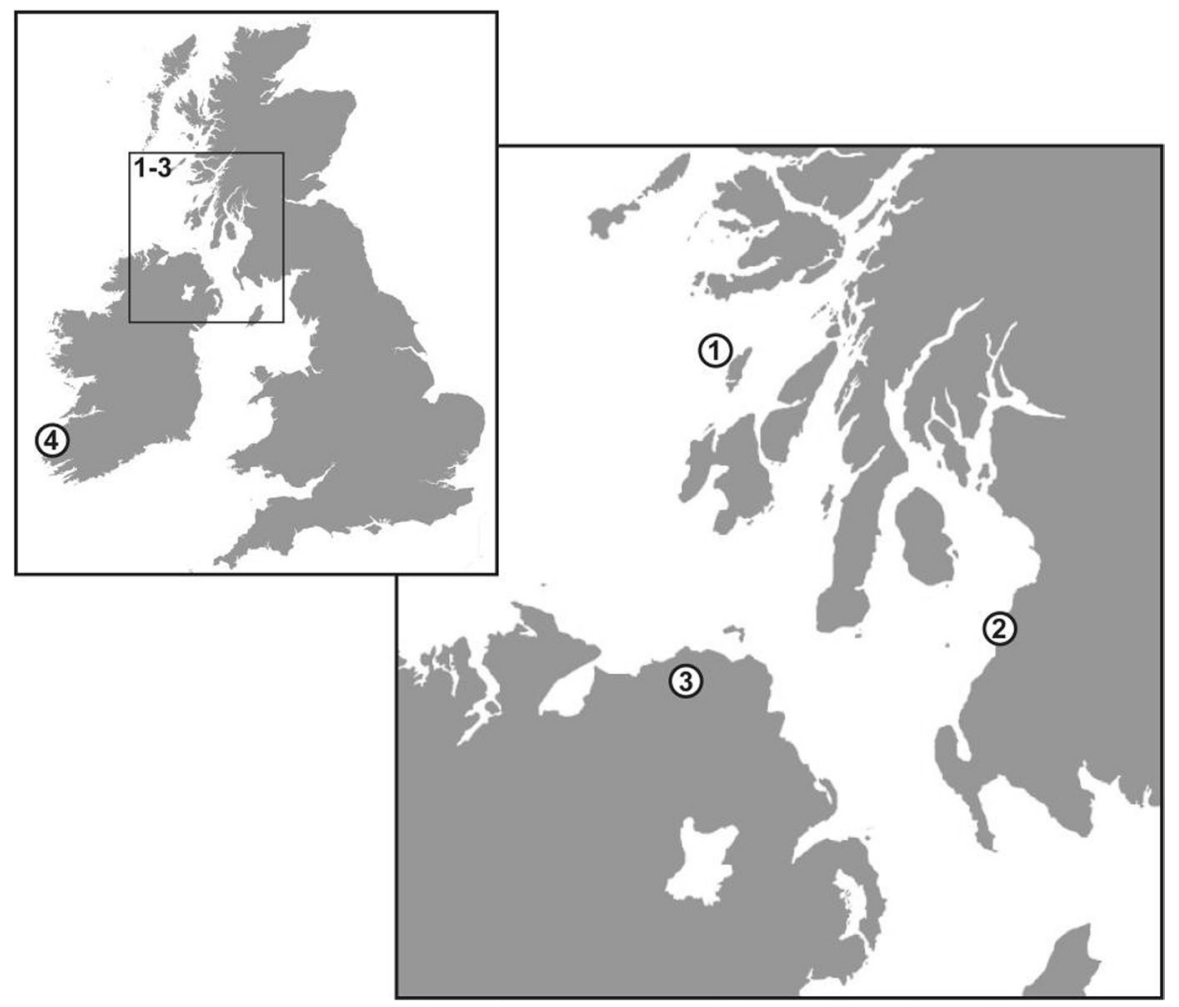

Fig. 1 Location of key sites discussed in the text: 1. Cnoc Coig, Oronsay, Inner Hebrides (Scotland); 2. Gallow Hill and Little Hill Bridge, Ayrshire (Scotland); 3. Loughan Island, Lower River Bann, Co. Londonderry (Ireland); 4. Ferriter's Cove, Co. Kerry (Ireland)

antler, shell, and stone artefacts (Meiklejohn et al. 2005). A small number of disarticulated human remains (49 fragments), representing at least three adults and a child, were deposited in five diffuse groups within the midden material (Meiklejohn et al. 2005). Almost all areas of the skeleton are represented in the assemblage as a whole, with fragments deriving from the skull (cranium and teeth); the torso (clavicle, cervical vertebrae, rib, pelvis); and the upper and lower limbs (metacarpals, hand phalanges, a possible fragment of the patella, tibia, metatarsals and foot phalanges). Various scholars have argued that these remains most likely represent exposure of bodies on the midden, where the larger bones were taken away and elements from the torso and the more loosely articulated extremities were left behind (see Pollard 1996; Bradley 1997; Telford 2002; King 2003; Gray Jones 2011). Meiklejohn et al. (2005, p. 102), however, reject the idea of exposure of bodies on the midden and consider the groups of remains to represent two processes: one which is the result of a random, non-cultural, taphonomic process responsible for similar 'loose' scattered/disarticulated remains found on 
sites across Europe; and a second, non-random, cultural pattern that is dominated by hand and foot bones and not previously reported in the European Mesolithic.

Whether they involved in situ exposure of bodies or the transportation of remains from elsewhere, these acts of deposition brought together the remains of people, with the bodies of animals, materials and things from their world. The clearest example of this is the close association of one group of human bones (group 2), dominated by hand and foot bones and representing parts of at least three different people, with a group of seal bones, including part of the rear flipper of an adult grey seal (Nolan 1986, p. 255). Meiklejohn et al. (2005, pp. 102-103) suggest that these human and seal bones are symbolically linked together in common burial, resulting from the close association of these populations with the exploitation of seals, and a social focus on the sea more generally. We would go further in suggesting that this depositional act directly juxtaposes human hand and foot bones and seal flipper bones, creating a material dialogue between seals and humans which can be interpreted as articulating relational understandings of identity. Whilst we can explore seal identities in terms of their role as one of the main prey species for these groups, we can also suggest that these dialogues drew attention to seals as agentic beings engaged in human-non-human social relationships (see Overton and Hamilakis 2013, p. 114) and recognised broader aspects of this relationship. In the context of the communities inhabiting the island of Oronsay, these may include parallels or similarities drawn between seal and human 'persons', such as their similar abilities to perform both on land and in the water, and their fish-based diets (Cobb 2008; Gray Jones and Taylor, in press). The integration of dead seals and dead persons then may speak of a relational ontology, at this particular place and time, where the divide between humans and seals was blurred and fluid (Gray Jones and Taylor, in press).

These material dialogues were not necessarily restricted to seals, however. The collection and incorporation of human remains into the midden also brings them into association with other things from this maritime world, other non-human persons, shellfish and materials of the shore and sea. The deposition of perforated cowrie shells, worn as body/hair ornaments or on clothing, for example, also points to entanglements between local materials and living human bodies. As monuments to consumption, perhaps middens were an appropriate place to express these relationships brought into being through the routines of daily life. However, not all of the human remains on Oronsay were integrated into the midden. Some body parts were removed and taken away. These elements may have been curated and used in the wider community and involved in other relationships and material acts. There is no complementary site on Oronsay, or in Scotland, where the missing elements have been found, but we can see ways in which material like this may have been circulated and used in Ireland. Here we can consider that, rather than representing a person or the dead in a general sense, these remains may have continued to possess agency and be animate after death, such that personal identity, or aspects of it, continued to be manifest and engaged with, not lost, after death.

Woodman $(2015$, p. 160) recently noted a bone point made on a human ulna from Loughan Island on the lower River Bann (Ireland), one of over 125 bone points recovered during dredging in the 1930s (see Fig. 1). These simple points are 
interpreted as projectile points for fish spears or as the teeth in eel leisters or rakes, and were found near natural fords where seasonal migrations of eel and salmon may have been intercepted (Woodman 2015, p. 160). To begin with, the decision to use human bone for this artefact is unlikely to have been accidental, and may have been intimately connected to the identity of the person whose bone it was. Whilst morphologically similar elements are found in other mammals, it is unlikely that Mesolithic people would not have been able to distinguish between these, given their familiarity with animal bone gained through butchery and the utilisation of animal materials for the manufacture of various items of material culture. What is more, the decision to use specific materials for particular tasks has been recorded in a number of other Mesolithic contexts. As Conneller notes, red deer antler was used exclusively for the production of barbed points at Star Carr (2011, p. 58), and we could also note the exclusive use of elk metapodia for bodkins and aurochs metapodia for scrapers (see Clark 1954). Similarly, Price (2009, p. 685) has argued that certain plants were used for the manufacture of specific types of artefacts in the Scandinavian Mesolithic.

In the same way that Conneller $(2011$, p. 62) suggests that the manufacture of barbed points at Star Carr harnessed deer affects, here at Loughan Island we can explore the possibility that this bone point also harnessed specific qualities of the person it derived from. This may stem from the material's origin as part of a specific person, imbued with their particular combination of age, gender, social relations, skills and abilities. Nelson notes, for example, that amongst the Koyukon of the Alaskan interior, luck is a nearly tangible essence that can be held, temporarily or permanently, passed on to others, and can infuse possessions (1983, pp. 26-27). It can be specific to certain activities, and we can envisage in this instance that the material remains of a person who held a history of luck or repeated success in fishing might make a lucky or more successful projectile point. The choice of this particular bone, the ulna, may also be significant. As part of the muscled forearm of a skilled fisher/hunter it may have harnessed that person's strength, technical skill or precision in this particular spearing activity (akin to the aggressive and resistant affects of deer antler [Conneller 2011, p. 62]). His/her history of success may have been with a particular species or even at this specific point on the river, such that the material from this person's bone also 'dragged' these past encounters along with it and presented opportunities for future success (Conneller 2011, p. 54). The use of human remains in negotiating hunting success is found amongst northern Eurasian and North American hunters and it is clear that in some societies the dead have agency in terms of enhancing hunting success (McNiven 2013, p. 104).

The variety of mortuary practices that we see in Mesolithic Britain and Europe, many of which involved engaging with the body in various states of decay, suggest that access to dead bodies or parts of them was often a required part of Mesolithic practice. Remains may have been curated specifically for later use, and we can see deposits of human bone at sites like Ferriter's Cove (Ireland) as examples of this (see Fig. 1). Small quantities of disarticulated and fragmented human remains were recovered in at least two concentrations within the occupation deposits (Woodman et al. 1999), which could be interpreted as caches of bone, similar to the caches of axes found at the site. Deposition of remains in accessible caves may also have 
ensured later access to them. In addition, whilst we can only trace the use of human bone, it is possible that other substances were also utilised from bodies placed in caves or exposed on middens. The Aleuts (indigenous people of the Aleutian Islands, Alaska), for example, kept the bodies of whale hunters and shamans in secret caves. As part of ritual preparations for whale hunting they would go to touch them and even apply 'fat or other tissues of corpses' to their bodies, kayaks and hunting weapons in an attempt to gain spiritual power (Black 1981, pp. 129-130, cited in McNiven 2013, p. 104). Body substances deriving from specific persons may have been important and potent materials for Mesolithic hunter-gatherers.

Rather than the dead becoming part of a homogenous 'ancestor' after death, the variability in how the body was treated and the different ways in which human remains were deposited suggest that identity was an important factor in these engagements, albeit one that did not rely on the maintenance of an individual body. The agency of the remains of the dead was a product of their identity in life, their skills, qualities, and relationships, and this was retained by their remains and bodily substances even once transformed by death. Whilst the body becomes physically partible after death, through its decay, decomposition and ultimate dissolution, this is not a simple reduction to its relational components and their redistribution back into the world, but instead a reconfiguration and continuation of these relationships and identities. Recent scholarship (e.g. Sofaer 2006) emphasises a life-course perspective and the plastic, pliable nature of the body - as we grow, age, learn or suffer from illness and injury - and the consequent non-static, fluid nature of identity throughout life. Why should this stop at death? Through engagements with the living, and dialogues with places, landscapes, animals and materials, the identity of the dead continued to be formulated after death.

\section{People, Things, Places and Assemblages}

To resituate the dead as affective in the identities of the living, however, requires considering in more detail how personhood was created in life. The idea of multiply authored personhood engendered through the materiality of Mesolithic life, as reviewed above, provides an important starting point for considering the specifics of Mesolithic identity. In addition, Cobb (2008, 2013) has drawn upon phenomenological landscape archaeology (e.g. Tilley 1994; Cummings and Whittle 2003) to examine how sites incorporated and garnered importance from wider landscape features. This is certainly the case for some of the exceptional sites of Mesolithic Britain and Ireland, such as the Oronsay middens. However, we argue, the principles of this approach are just as applicable, and perhaps most effective in the Mesolithic, when considering identity at the level of the daily round. If we begin with the argument that Mesolithic personhood was likely constructed through multiple authorship, considering landscapes and parts of place as part of this provides a further dimension to Mesolithic identity.

Take, for example, a single site, such as the spread of Mesolithic material around Gallow Hill (Donnelly and Macgregor 2005) and the nearby Littlehill Bridge (Macgregor and Donnelly 2001) on the Ayrshire coast, southwest Scotland (see 
Fig. 1). Here, on the edge of a hill, on the raised beach, to the north of the once lagoonal and estuarine area at the mouth of the Water of Girvan (Donnelly and Macgregor 2005), both fieldwalking and excavation have revealed surface scatters of Mesolithic material extending over approximately $0.5 \mathrm{~km}^{2}$, a series of mixed, unstratified Mesolithic deposits, in situ scattered lithic material and open site activity including pits, hearths, areas of burning, stake holes and several sub-oval, shallow-sided scoops (MacGregor and Donnelly 2001, p. 5). Radiocarbon dates and the accumulated material suggest that it was potentially revisited over a period of at least 1500 years in the late Mesolithic, and the excavators have pointed to a focus on specialised blade and microlith production and the repair of microlithic tools at the site (Donnelley and MacGregor 2005, pp. 56, 58).

Given that both the place as a whole and specific areas of it were so regularly reused over such a long period, for daily life and specific activities such as tool-making and mending, we can consider how this was key to the construction of different identities. Further, landscape setting may have played an important role (Cobb 2008, 2013). For example, a wide range of raw materials from a wide range of sourcessuch as pitchstone from the Isle of Arran-were being brought to and worked at the site (Donnelley and MacGregor 2005, p. 50). These materials in themselves would have served as visceral reminders of journeys, disclosing an understanding of places and people across, entwined with and connected by the sea, or by the valleys through which they had been brought. In addition, the location of the site and the visual connections it affords would have worked to connect these activities to activities and identities constructed elsewhere. For instance, there are superb views from the site both inland over the Midland Valley, and out to the Firth of Clyde, the northern Irish Sea, the islands of Arran and Ailsa Craig (which can clearly be seen from the Antrim Coast) and much of Argyll and Bute, as well as the edges of the Southern Uplands. We could regard this site as a hub, then, where a series of material and visual connections across the land and the sea and across time too, were entwined into the rhythms of daily life, and thus the making, doing and being through which people's identities were performed and negotiated. Whilst we point to this site-specific example here, it is important to emphasise that this kind of approach is equally applicable on a broader scale (e.g. see Cobb 2008).

In the past Cobb has characterised these relationships in phenomenological terms (Cobb 2008, 2014), but more recently (Cobb 2015) she has moved toward a non-anthropocentric way to explore these relationships, through the ideas of Deleuze and Guattari (1987), and particularly DeLanda's (2006) development of the notion of assemblage theory. This perspective argues that people, things and places come together to comprise assemblages which are more than the sum of their parts. Assemblages can be amorphous, loose and fleeting collections of things and bodies (e.g. the assemblage of the hunt: the trees, the animal, the wind, the hunters, the microliths, the wood in which they are hafted), or they can be longer lasting (e.g. the assemblage of the shell midden), and they can exist at any scale, from intimate social settings, to the broader assemblage of the European Mesolithic. The constituents of an assemblage can, at any one time, be or cease to be constituents of other assemblages, which may not necessarily change the assemblage itself. This means that assemblages are always in process, always 
becoming, and thus lend themselves toward considering how identities are always in formation. Further, no assemblage exists in a vacuum, but rather assemblages garner vibrancy (vide Bennett 2010) in relationship to other assemblages, past present and future (for a more thorough explanation see Harris 2014, 2016). If we take this approach we can consider how plants, animals, stones, places, seas, boats, the living and the dead, entwine to form assemblages, vibrant in their being, and affective in the constitution of Mesolithic identity. Let us return to the Oronsay middens to consider this further.

As we have already shown, Cnoc Coig was a place for the transformation of bodies in death, both human and seal. But we can go further in considering the transformational properties of this midden by interrogating other materials. For instance, the distribution of faunal remains has led to the suggestion that land animals, such as deer and boar, were brought to the Oronsay middens in an already semi-butchered state, before becoming highly fragmented within the middens (Grigson and Mellars 1987). It follows that the middens may have enabled a similar transformation of these other land based bodies. Meanwhile, fish and animals associated with the sea (e.g. cetaceans and otter) were more regularly found in articulated states, with far more of their skeletal parts present. Moreover, fish and sea animals were associated predominantly with contexts of burning, whilst land animals were not (Grigson and Mellars 1987). Approaching these observations through assemblage theory allows us to understand how the 'assemblage of animals and humans, the materials they produce together, and the materials brought in from elsewhere produced the midden at Cnoc Coig' (Harris 2014, p. 336). But we argue that we can go further, because, for these two very different types of transformation to occur indicates that multiple assemblages are enmeshed here. There are assemblages of land, assemblages of sea, the assemblage of the midden itself, assemblages of journeys out to sea, across the sea, and in other lands (the Priory Midden on Oronsay is, for example, aligned with the Paps of Jura [Cobb 2008]). Each points to how different identities may have been in process, how they were at once transformed and contributed to the transformation of other identities by being brought to the midden context (which in turn contributed to the transformative nature of the midden assemblage), and how they were likely extended back into other assemblages. The lack of larger human bones, for instance, suggests that through their removal from the midden, the transformation of human bodies continued elsewhere, potentially with the bones acting as media to transform the identities of persons and animals beyond the middens (Cobb 2008, p. 281).

Taking an assemblage approach shifts how we might view identity at Cnoc Coig, from a relational collection of permeable or partible parts of persons, to a series of vibrant and enmeshed components, existing on a range of temporal and spatial scales and ontologically equal in the affects that they elicit. Further, an assemblage approach allows us to move beyond the idea of middens as a series of palimpsests, as moments of visitation punctuated by periods of absence of activity to be disregarded. Instead if we characterise this as a place where multiple assemblages were continually territorialised and actualised, we can reconsider this as a constant process. This suggests how Cnoc Coig (and the assemblage of Oronsay itself) may have been a powerful place in Mesolithic cosmologies, even when people were not 
present, further helping us to understand its power as a place for the transformation of identities.

\section{Conclusions: Future Approaches to Mesolithic Identity}

In Finlay's (2006) review of identity in the Mesolithic, the concept of personhood and relational identities was in its infancy in its application to the Mesolithic. A decade later, it is clear that this approach opened a new way forward for thinking through the evidence for identity in the period. We argue that an assemblage approach takes the next step. There is extensive evidence to suggest that Mesolithic ontologies were fundamentally relational, but ultimately personhood approaches are still inherently anthropocentric. An assemblage approach allows us to consider the people in whom we are so interested, while also regarding them as partners with, and products of, the multiple materials and places that constituted the Mesolithic world. In turn this enables a non-normative approach to identity, which is a productive way of working through the archaeological material to understand how Mesolithic personal identities were created in life and in death.

Furthermore, an assemblage approach undercuts the dichotomy between science and theory as it places them 'on a single ontological footing, and does not regard them as two separate parts of an enterprise' (Harris 2014, p. 333; see also Sofaer 2006). This provides important scope for the future of identity studies in the Mesolithic, allowing archaeologists to reconcile socially-situated narratives with advances in biological and biomolecular archaeology. The study of stable isotopes for reconstructing patterns in diet, for example, has long been a core element of Mesolithic (and Neolithic) studies, particularly focused on changes in subsistence around the Mesolithic-Neolithic transition. An assemblage approach to stable isotopic data enables us to consider the affective properties of animals and plants, and where such work proposes interpretations related to group/community identities through the identification of regional patterns of subsistence (e.g. Schulting 2009), assemblage theory can help us to reconsider the non-human components of such communities in ontologically equal terms. The same is true of work in other biomolecular techniques such as zooarchaeology by mass spectrometry (ZooMS) and aDNA analysis. Thus, there is still much potential here for critical appreciations of this data that move beyond modern, Western, conceptions of individual identity and group dynamics, and rather than broad temporal and spatial scales, investigate past diet and genetic patterning at scales that relate to individual past lives (Milner 2006, p. 68). Equally, traditional macroscopic analyses have proved productive for new understandings of relational personhood in the British and Irish Mesolithic, with researchers taking new, social, approaches to traditional data, such as faunal remains (e.g. Overton 2014, 2018) and palaeoenvironmental data (e.g. Taylor 2012, 2018), to explore the role of human-animal and human-environment relationships in Mesolithic identities.

In this paper we have stressed the importance of moving beyond normative Western conceptions of identity if we want to reconsider this subject in new and radical ways, and we have worked through a selection of evidence to illuminate how 
this is possible. To conclude, however, we argue that to think radically about past Mesolithic identities we also need to think radically in our contemporary practice. Until recently, Mesolithic studies in Britain and Ireland (and beyond) have remained extraordinarily hierarchical, and often patriarchal and parochial. Under these conditions it is no surprise that narratives based on normative Western values have been perpetuated in our interpretations of Mesolithic identity. To propose radical new approaches to identity in the past, however, requires us to push the boundaries of our identities as Mesolithic scholars in the present. This requires us to move beyond our patriarchal past, and to create a (feminist) culture of supportive scholarly multivocality, allowing science and theory to be enmeshed and therefore encouraging one another to experiment with new and non-normative approaches. Ultimately, it is only with a culture of such scholarly support in our contemporary practice that we can truly realise the potential of non-normative interpretations of identity for the Mesolithic.

Acknowledgements We would like to thank the editors of this special issue, Ben Elliott and Aimée Little, for inviting us to contribute this paper, and Graeme Warren and Chantal Conneller for inviting us to participate in the TAG session upon which it is partly based. Some of the work above derives from our Doctoral research, funded by the Arts and Humanities Research Council (AGJ) and by the University of Manchester and the Royal Anthropological Institute (HC), to whom we are extraordinarily grateful. Both of our theses were supervised by Chantal Conneller, to whom we owe a great debt of thanks for supporting us in these endeavours. In addition AGJ would also like to thank Barry Taylor for comments on the text, and $\mathrm{HC}$ would like to thank Oliver Harris for extended conversations on assemblage theory.

Open Access This article is distributed under the terms of the Creative Commons Attribution 4.0 International License (http://creativecommons.org/licenses/by/4.0/), which permits unrestricted use, distribution, and reproduction in any medium, provided you give appropriate credit to the original author(s) and the source, provide a link to the Creative Commons license, and indicate if changes were made.

\section{References}

Bennett, J. (2010). Vibrant matter: A political ecology of things. Durham: Duke University Press.

Bradley, R. (1997). Domestication as a state of mind. Analecta Praehistorica Leidensia, 29, 13-17.

Charlton, S. J. L. (2016). Lifeways at the Mesolithic-Neolithic transition: Integrating new biomolecular approaches to skeletal material in Britain. Unpublished Ph.D. thesis, University of York.

Clark, G. A., \& Neeley, M. (1987). Social differentiation in European Mesolithic burial data. In P. Rowley-Conwy, M. Zvelebil, \& P. Blankhom (Eds.), Mesolithic northwest Europe: Recent trends (pp. 121-127). Sheffield: Department of Archaeology, University of Sheffield.

Clark, J. G. D. (1954). Excavations at Star Carr. Cambridge: Cambridge University Press.

Cobb, H. L. (2005). Straight down the line? A queer consideration of hunter-gatherer studies in northwestern Europe. World Archaeology, 37(4), 630-636.

Cobb, H. L. (2008). Media for movement and making the world: An examination of the Mesolithic experience of the world and the Mesolithic to Neolithic transition in the Northern Irish Sea basin. Ph.D. thesis, University of Manchester.

Cobb, H. L. (2013). Disclosing the world during the Mesolithic/Neolithic transition in the Irish Sea basin. In M. Larsson \& J. Debert (Eds.), North-west Europe in transition: The early Neolithic in Britain and southern Sweden (pp. 55-62). Oxford: Archaeopress (British Archaeological Reports).

Cobb, H. L. (2014). Materials, biographies, identities, experiences: New approaches to materials in hunter-gatherer studies. In V. Cummings, P. Jordan, \& M. Zvelebil (Eds.), The Oxford handbook of the archaeology and anthropology of hunter-gatherers (pp. 1204-1220). Oxford: Oxford University Press. 
Cobb, H. L. (2015). Why the Mesolithic needs assemblages. In K. Franklin, J. Johnson, E. Miller-Bonney, \& L. Smejda (Eds.), Towards incomplete archaeologies? Oxford: Oxbow.

Conneller, C. (2004). Becoming deer: Corporeal transformations at Star Carr. Archaeological Dialogues, $11(1), 37-56$.

Conneller, C. (2005). Moving beyond sites: Mesolithic technology in the landscape. In N. Milner \& P. Woodman (Eds.), Mesolithic studies at the beginning of the 21st century (pp. 42-55). Oxford: Oxbow.

Conneller, C. (2006). Death. In C. Conneller \& G. Warren (Eds.), Mesolithic Britain and Ireland: New approaches (pp. 139-164). Stroud: Tempus.

Conneller, C. (2011). An archaeology of materials: Substantial transformations in early prehistoric Europe. Abingdon: Routledge.

Craib, I. (1998). Experiencing identity. London: Sage Publications.

Cummings, V., \& Whittle, A. (2003). Places of special virtue: Megaliths in the Neolithic landscapes of Wales. Oxford: Oxbow.

Dahlberg, F. (Ed.). (1981). Woman the gatherer. New Haven: Yale University Press.

DeLanda, M. (2006). A new philosophy of society: Assemblage theory and social complexity. London: Continuum.

Deleuze, G., \& Guattari, F. (1987). A thousand plateaus: Capitalism and schizophrenia. Minneapolis: University of Minnesota Press.

Dobres, M. (2000). Technology and social agency: Outlining a practice framework for archaeology. Oxford: Blackwell.

Donnelly, M., \& MacGregor, G. (2005). The excavation of Mesolithic activity, Neolithic and Bronze Age burnt mounds and Roman-British ring groove houses at Gallow Hill, Girvan. Scottish Archaeological Journal, 27(1), 31-69.

Finlay, N. (2003). Microliths and multiple authorship. In L. Larsson, H. Kindgren, K. Knutsson, D. Loeffler, \& A. Akerlund (Eds.), Mesolithic on the move: Papers presented at the 6th International Conference on the Mesolithic in Europe, Stockholm, 2000 (pp. 169-176). Oxford: Oxbow.

Finlay, N. (2006). Gender and personhood. In C. Conneller \& G. Warren (Eds.), Mesolithic Britain and Ireland: New approaches (pp. 25-60). Stroud: Tempus.

Finlay, N. (2014). Personhood and social relations. In V. Cummings, P. Jordan, \& M. Zvelebil (Eds.), The Oxford handbook of the archaeology and anthropology of hunter-gatherers (pp. 1191-1203). Oxford: Oxford University Press.

Fowler, C. (2004). The archaeology of personhood: An anthropological approach. London: Routledge.

Gray Jones, A. (2011). Dealing with the dead: Manipulation of the body in the mortuary practices of Mesolithic north-west Europe. Ph.D. thesis, University of Manchester.

Gray Jones, A., \& Taylor, B. (in press). Seals by day: Mesolithic maritime identities on the west coast of Scotland.

Grigson, C., \& Mellars, P. A. (1987). The mammalian remains from the middens. In P. Mellars (Ed.), Excavations on Oronsay: Prehistoric human ecology on a small island (pp. 243-289). Edinburgh: Edinburgh University Press.

Grøn, O. (1995). The Maglemose culture: A reconstruction of the social organisation of a Mesolithic culture in northern Europe. British Archaeological Reports International Series S616. Oxford: Archaeopress.

Grøn, O. (2003). Mesolithic dwelling places in south Scandinavia: Their definition and social interpretation. Antiquity, 77, 685-708.

Harris, O. J. T. (2014). Revealing our vibrant past: Science, materiality and the Neolithic. In A. Whittle \& P. Bickle (Eds.), Early farmers: The view from archaeology and science (pp. 327-345). Oxford: Proceedings of the British Academy.

Harris, O. J. T. (2016). Becoming post-human: Identity and the ontological turn. In E. Pierce, A. Russell, A. Maldonado, \& L. Campbell (Eds.), Creating material worlds: The uses of identity in archaeology (pp. 17-37). Oxford: Oxbow.

Heidegger, M. (1962 [1927]). Being and time. Oxford: Blackwell.

Hellewell, E. (2015). An investigation into the placement of disarticulated human remains into shell middens during prehistory. Ph.D. thesis, University of York.

King, M. (2003). Unparalleled behaviour: Britain and Ireland during the 'Mesolithic' and 'Neolithic'. Oxford: Archaeopress.

MacGregor, G., \& Donnelly, M. (2001). A Mesolithic scatter from Littlehill Bridge, Girvan, Ayrshire. Scottish Archaeological Journal, 23(1), 1-14. 
McNiven, I. J. (2013). Between the living and the dead: Relational ontologies and the ritual dimensions of dugong hunting across Torres Strait. In C. Watts (Ed.), Relational archaeologies: Humans, animals, things (pp. 97-116). Abingdon: Routledge.

Meiklejohn, C., Chamberlain, A. T., \& Schulting, R. J. (2011). Radiocarbon dating of Mesolithic human remains in Great Britain. Mesolithic Miscellany, 21, 20-58.

Meiklejohn, C., Merrett, D. C., Nolan, R. W., Richards, M. P., \& Mellars, P. A. (2005). Spatial relationships, dating and taphonomy of the human bone from the Mesolithic site of Cnoc Coig, Oronsay, Argyll, Scotland. Proceedings of the Prehistoric Society, 71, 85-105.

Meiklejohn, C., \& Woodman, P. C. (2012). Radiocarbon dating of Mesolithic human remains in Ireland. Mesolithic Miscellany, 22(1), 22-41.

Mellars, P. A. (1987). Excavations on Oronsay: Prehistoric human ecology on a small island. Edinburgh: Edinburgh University Press.

Milner, N. J. (2006). Subsistence. In C. Conneller \& G. Warren (Eds.), Mesolithic Britain and Ireland: New approaches (pp. 61-82). Stroud: Tempus.

Murphy, E. M. (1996). Possible gender labour divisions at the Mesolithic site of Mount Sandel, Co., Londonderry, Northern Ireland. Kvinner Arkeologi Norge, 21, 103-124.

Nelson, R. K. (1983). Make prayers to the raven: A Koyukon view of the northern forest. Chicago: University of Chicago Press.

Nilsson Stutz, L. (2003). Embodied rituals and ritualized bodies: Tracing ritual practices in late Mesolithic burials. Stockhom: Almqvist \& Wiksell International.

Nolan, R. W. (1986). Cnoc Coig: The spatial analysis of a late Mesolithic shell midden in western Scotland. Ph.D. thesis, University of Sheffield.

O'Shea, J., \& Zvelebil, M. (1984). Oleneostrovski Mogilnik: Reconstructing the social and economic organisation of prehistoric foragers in northern Russia. Journal of Anthropological Archaeology, $3,1-40$

Overton, N. J. (2014). Memorable meetings in the Mesolithic: Tracing the biography of human-nonhuman relationships in the Kennet and Colne Valleys with social zooarchaeology. Ph.D. thesis, University of Manchester.

Overton, N. J. (2018). The rhythm of life: Exploring the role of daily and seasonal rhythms in the development of human-nonhuman relationships in the British early Mesolithic. In S. PilaarBirch (Ed.), Multispecies archaeology (pp. 295-309). London: Routledge.

Overton, N. J., \& Hamilakis, Y. (2013). A manifesto for a social zooarchaeology: Swans and other beings in the Mesolithic. Archaeological Dialogues, 20(2), 111-136.

Pollard, A. (1996). Time and tide: Coastal environments, cosmology and ritual practice in early prehistoric Scotland. In A. Pollard \& A. Morrison (Eds.), The early prehistory of Scotland (pp. 198-210). Edinburgh: Edinburgh University Press.

Price, S. (2009). Wood and wild animals: Towards an understanding of a Mesolithic world. In S. McCartan, R. Schulting, G. Warren, \& P. Woodman (Eds.), Mesolithic horizons (pp. 683-689). Oxford: Oxbow Books.

Robb, J., \& Harris, O. J. T. (Eds.). (2013). The body in history: Europe from the Palaeolithic to the future. Cambridge: Cambridge University Press.

Schmidt, R. A. (2005). The contribution of gender to personal identity in the southern Scandinavian Mesolithic. In E. C. Casella \& C. Fowler (Eds.), The archaeology of plural and changing identities: Beyond identification (pp. 79-108). New York: Kluwer Academic/Plenum Publishers.

Schulting, R. J. (2009). Worm's Head, Caldey Island (South Wales, UK) and the question of Mesolithic territories. In S. McCartan, R. Schulting, G. Warren, \& P. Woodman (Eds.), Mesolithic horizons (pp. 354-361). Oxford: Oxbow.

Schulting, R. J., Bello, S. M., Chandler, B., \& Higham, T. F. G. (2015). A cut-marked and fractured Mesolithic human bone from Kent's Cavern, Devon, UK. International Journal of Osteoarchaeology, 25, 31-44.

Schulting, R. J., \& Richards, M. P. (2001). Dating women and becoming farmers: New palaeodietary and AMS dating evidence from the Breton Mesolithic cemeteries of Téviec and Hoëdic. Journal of Anthropological Archaeology, 20, 314-344.

Sofaer, J. (2006). The body as material culture: A theoretical osteoarchaeology. Cambridge: Cambridge University Press.

Strassburg, J. (2000). Shamanic shadows: One hundred generations of undead subversion in southern Scandinavia, 7000-4000 BC. Stockholm: Stockholm University. 
Taylor, B. (2012). The occupation of wetland landscapes during the British Mesolithic: Case studies from the Vale of Pickering. Ph.D. thesis, University of Manchester.

Taylor, B. (2018). Subsistence, environment and Mesolithic landscape archaeology. Cambridge Archaeological Journal. https://doi.org/10.1017/S0959774318000021.

Telford, D. (2002). The Mesolithic inheritance: Contrasting Neolithic monumentality in eastern and western Scotland. Proceedings of the Prehistoric Society, 68, 289-315.

Thomas, J. (2004). Archaeology and modernity. London: Routledge.

Tilley, C. (1994). A phenomenology of landscape: Places, paths and monuments. Oxford: Berg.

Warren, G. M. (2006). Technology. In C. Conneller \& G. Warren (Eds.), Mesolithic Britain and Ireland: New approaches (pp. 13-34). Stroud: Tempus.

Woodman, P. C. (2015). Ireland's first settlers: Time and the Mesolithic. Oxford: Oxbow.

Woodman, P. C., Anderson, E., \& Finlay, N. (1999). Excavations at Ferriter's Cove 1983-1995: Last foragers, first farmers in the Dingle Peninsula. Bray: Wordwell. 